\title{
An attempt to make lipid-lowering therapy more effective in Hungary. The results of MULTI GAP 2010 and the PLUS Program
}

\author{
Laszlo Mark¹, György Paragh², Istvan Karadi³, Istvan Reiber ${ }^{4}$, Gyula Pados ${ }^{5}$, Zoltan Kiss ${ }^{6}$
}

\author{
${ }^{12 \text { nd }}$ Department of Medicine - Cardiology, Pandy Kalman Bekes County Hospital, \\ Gyula, Hungary \\ $21^{\text {st }}$ Department of Medicine, Medical and Health Science Centre, University of \\ Debrecen, Hungary \\ $33^{\text {rd }}$ Department of Medicine, Semmelweis University, Budapest, Hungary \\ $4^{4 \text { th }}$ Department of Medicine, St. George Fejer County Hospital, Szekesfehervar, \\ Hungary \\ Independent Department of Lipidology, St. Imre Hospital, Budapest, Hungary \\ ${ }^{6} \mathrm{MSD}$ Hungary Kft, Budapest, Hungary
}

Submitted: 20 May 2011

Accepted: 24 July 2011

Arch Med Sci 2011; 7, 5: 760-766

DOI: 10.5114/aoms.2011.25549

Copyright @ 2011 Termedia \& Banach

\begin{abstract}
Introduction: The primary goal of lipid-lowering therapy is the attainment of low-density lipoprotein cholesterol (LDL-C) target levels.

Material and methods: The MULTI GAP (MULTI Goal Attainment Problem) 2010 is a part of surveys started a few years ago, in which the lipid results of 1540 patients treated by general practitioners (GPs) and specialists were measured. The data were compared to the results of similar studies involving 15,580 patients between 2004 and 2009.

Results: In 2010 the mean LDL-C level ( \pm SD) of patients treated by GPs was found to be $3.01 \pm 1.0 \mathrm{mmol} / \mathrm{l}$. The target of $2.50 \mathrm{mmol} / \mathrm{l}$ was achieved by $32 \%$, with a mean LDL-C level of $2.84 \pm 1.0 \mathrm{mmol} / \mathrm{l}$ and an achievement rate of $39 \%$ in patients treated by specialists. The results of comparisons starting from 2004 showed a marked improvement every year in the beginning, but in the last 3 years stagnation was observed. In 2010 in addition to the MULTI GAP main study, a group of physicians took part in special training called the Plus Program. As a result of this, the LDL-C level was $0.18 \mathrm{mmol} / /$ lower in 114 of the GPs' patients $(p=0.088)$ and $0.27 \mathrm{mmol} / \mathrm{l}(p<0.0001)$ lower in 313 of the specialists' patients, with a significantly better, $42 \%(p=0.045)$ and $50 \%(p=0.001)$, goal attainment rate, respectively.

Conclusions: The 2010 MULTI GAP study shows that the quality of lipid-lowering therapy in Hungary seems to be in stagnation. The results of the PLUS Program suggest that continuous training of doctors is the key to further improvement.
\end{abstract}

Key words: prevention, risk factors, hypercholesterolaemia, LDL cholesterol.

\section{Introduction}

Despite the clear improvement in recent years, cardiovascular disease (CVD) continues to be the leading cause of death in mortality statistics [1] Coronary heart disease (CHD) is a global epidemic and its prevention is one of the biggest challenges in contemporary medicine. The European Heart Health Charter highlights that beside the increasing funding spent

\author{
Corresponding author: \\ Laszlo Mark MD, PhD \\ $2^{\text {nd }}$ Department of Internal \\ Medicine - Cardiology \\ Pandy Kalman Bekes \\ County Hospital \\ Semmelweis u. 1. \\ P.O. Box 46, 5701 Gyula, \\ Hungary \\ Phone: $+36-209288053$ \\ Fax: +36-66526543 \\ E-mail: mark@pandy.hu
}


for the treatment of CVD in developed countries, a stronger emphasis should be placed on prevention [2, 3]. The recommendations and the cardiovascular prevention in daily practice should be bridged as soon as possible [4].

It is a well-known fact that the main reasons leading to the development of CHD are related to lifestyle. This is supported by the INTERHEART study carried out in 52 countries which proved that several well-defined and reversible risk factors are responsible for $90 \%$ of heart attacks [5]. One of the most important risk factors is hyperlipidaemia. Lipid-lowering therapy has outstanding importance in the treatment of high-risk patients. What is the situation of lipid-lowering therapy in Hungary and how could the quality of treatment be improved further? Based on the results of surveys carried out systematically since 2004 by general practitioners (GPs) and specialists among high-risk patients, the frequencies of target level attainment and alterations of lipid-lowering treatments are comparable. Besides presenting these results and those of MULTI GAP (MULTI Goal Attainment Problem) 2010, the recent data are compared to those observed in patients of a group of physicians who received special training.

\section{Material and methods}

The trends in lipid-lowering treatment were studied using surveys (CEL Program 2004 and 2005, KONSZENZUS-CEL Program 2006, REALITY 2004 and 2007 studies, MULTI GAP 2008 and 2009) performed on high cardiovascular risk patients of GPs and specialists in Hungary. From the period between 2004 and 2008, the data of 12317 [6], and from MULTI GAP 2009 those of 3563 patients [7] were processed.

In the MULTI-GAP 2010 study we analysed data and treatment strategies of 1540 patients from 136 specialists and 47 GPs (10-15 patients per physician were enrolled) using a structured questionnaire. The previous publication on 2010 data [8] did not separate the patients of the main study from those of the Plus Program, and in this study we used only the data of the patients being conformed with the former publications. The patients gave their consent to participate; the study was conducted in accordance with the Declaration of Helsinki and ICH-GCP (International Conference on Harmonisation - Good Clinical Practice).

Out of physicians participating in MULTI GAP 2010, 26 specialists and 9 GPs also took part in the PLUS Program with 397 and 117 patients, respectively. In this framework, these colleagues received special education related to lipid treatment, attended lectures on the guidelines of the Hungarian consensus conference [9], and received written material related to this topic as well. They were supplied with a calculator to determine the low-density lipoprotein cholesterol (LDL-C) level and also with software to analyse target level achievements which showed the proportion of treated patients attaining the target level in their whole practice, thus helping therapy and drawing attention to the insufficiencies of lipid-lowering therapy.

The whole MULTI GAP patient group (including the Plus Program patients) included 197 cases of unstable angina, 590 cases of previous myocardial infarction, 275 cases of vascular operation due to peripheral arterial disease, 432 cases of stroke and 275 of transient ischaemic attack, 924 diabetic patients and 1770 with hypertension. The existence and extent of smoking, as well as the sex, age, body mass index (BMI) and waist circumference were recorded. 842 women and 1125 men participated in the study; their mean age was $64.4 \pm 10$ years. The doctors also estimated patient compliance based on frequency of statin prescription, the patients' knowledge and questioning the patients.

The risk classification of patients was performed according to the $4^{\text {th }}$ Hungarian Cardiovascular Consensus Conference recommendations [9]. All patients belonged to the high cardiovascular risk category, and because they also had a history of vascular events and/or were diabetic, they had $\mathrm{LDL}-\mathrm{C}$ targets of $\leq 2.50 \mathrm{mmol} / \mathrm{l}$.

\section{Statistical analysis}

For categorical variables we used frequencies of valid cases. For continuous variables means and medians are presented. Significance tests were performed by $\chi^{2}$ test for categorical and by ANOVA for continuous variables (with Fisher's least significant difference test method for multiple comparisons). Asymmetric 2-sided scores were considered. Values of $p$ (two-tailed) below 0.05 were accepted as significant. All statistical analyses were performed by SPSS.

\section{Results}

The MULTI GAP 2010 main study involved 1540 patients. The GPs' patients had a mean LDL-C level $( \pm \mathrm{SD})$ of $3.01 \pm 1.0 \mathrm{mmol} / \mathrm{l}$, while those of the specialists had $2.84 \pm 1.0 \mathrm{mmol} / \mathrm{l}$. Figure 1 demonstrates changes of LDL-C level between 2004 and 2010, showing a decrease of $0.77 \mathrm{mmol} / \mathrm{l}$ for patients treated by GPs whereas in patients treated by specialists a decrease of $0.50 \mathrm{mmol} / \mathrm{l}$ could be observed during this 7 -year period. In $2010,32 \%$ of the GPs' patients achieved the $2.50 \mathrm{mmol} / \mathrm{LDL}-\mathrm{C}$ target value, while for patients treated by specialists the corresponding proportion was 39\%; Figures 2 and 3 show changes in rates of patients achieving the target levels. In addition to the MULTI 


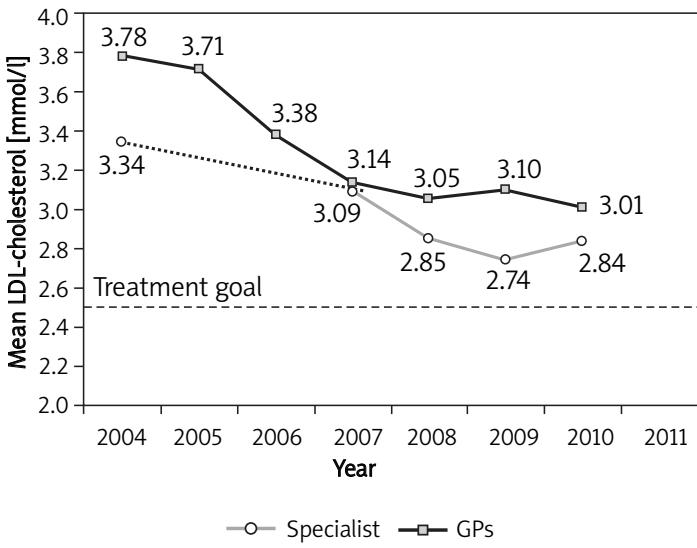

Figure 1. Change in mean LDL-cholesterol levels of high cardiovascular risk patients treated by GPs and specialists, over the years

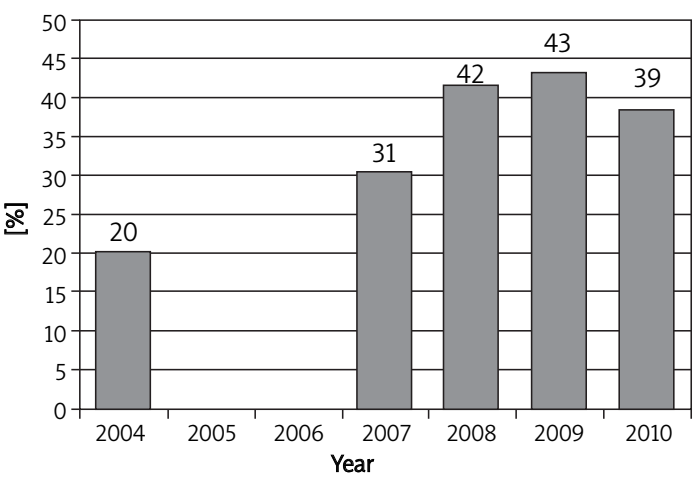

Figure 3. Changes in the ratio of patients reaching the target $2.5 \mathrm{mmol} / \mathrm{l}$ of LDL-cholesterol level treated by specialists over the last years

GAP main study, a group of doctors underwent special training in 2010, called the Plus Program. Table I shows the mean LDL-C level of the 427 patients treated by GPs and specialists and the percentage of them achieving the level of 2.50 $\mathrm{mmol} / \mathrm{l}$. The GP patients experienced a reduction of $0.18 \mathrm{mmol} / \mathrm{l}$ in their mean LDL-C level, while those of specialists had a decrease of $0.27 \mathrm{mmol} / \mathrm{l}$. Accordingly, a significant (10\% and $11 \%)$ increase occurred in the $2.50 \mathrm{mmol} / \mathrm{L}$ LDL-C attainment rate in both GPs' and specialists' patients (increasing to $42 \%$ and $50 \%$, respectively). Table II presents the

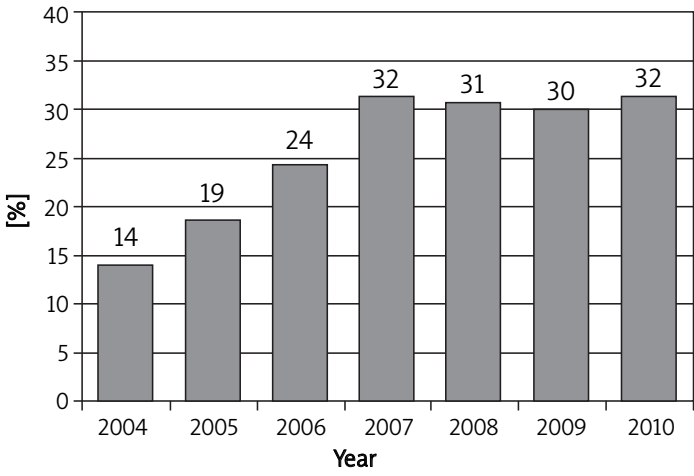

Figure 2. Changes in the ratio of patients reaching the target $2.5 \mathrm{mmol} / \mathrm{l}$ of LDL-cholesterol level treated by GP's over the last years

mean body mass index values and the occurrence of hypertension, smoking and diabetes in the MULTI GAP 2010 basic study and the PLUS Program in the patient groups treated by GPs and specialists. Also shown are the values of significance between the MULTI GAP 2010 study and the Plus Program and between the GPs' and specialists' patients.

In our study we separated male and female groups when analysing the mean LDL-C levels. These, along with the mean BMI values, and the occurrence of hypertension, smoking and diabetes in the two genders are presented in Table III. The LDL-C in women was $6.2 \%(0.17 \mathrm{mmol} / \mathrm{l})$ higher than the value considering all patients, and similar rates were found among male and female patients of physicians participating and not participating in the Plus Program $(0.15 \mathrm{mmol} / \mathrm{l}$ and $0.18 \mathrm{mmol} / \mathrm{l}$ difference, respectively). The 2010 MULTI GAP study also evaluated the physicians' lipid-lowering medical treatment compliance. This was based on questioning the patient and the frequency of drug prescriptions, and the result was given in percentage. Four groups were formed based on compliance: $70 \%$ or below, $71-80 \%, 81-90 \%$ and over $90 \%$ of patients were considered cooperative in each group, respectively. The $2.50 \mathrm{mmol} / \mathrm{LDL}-\mathrm{C}$ target achievement rate was 24\%, 31\%, 39\% and $41 \%$, respectively (Figure 4).

We examined what doses of statin were applied in the patients reaching or not reaching the target.

Table I. The mean LDL cholesterol and the achievement rate of $2.50 \mathrm{mmol} / \mathrm{l}$ target LDL cholesterol in the MULTI GAP 2010 basic study and PLUS Program

\begin{tabular}{|c|c|c|c|c|c|c|}
\hline & \multicolumn{3}{|c|}{ GPs } & \multicolumn{3}{|c|}{ Specialists } \\
\hline & $\begin{array}{l}\text { Patient } \\
\text { number }\end{array}$ & $\begin{array}{l}\text { LDL cholesterol } \\
\text { level [mmol/l] }\end{array}$ & $\begin{array}{c}\text { Target } \\
\text { achieve- } \\
\text { ment [\%] }\end{array}$ & $\begin{array}{l}\text { Patient } \\
\text { number }\end{array}$ & $\begin{array}{l}\text { LDL cholesterol } \\
\text { level [mmol/l] }\end{array}$ & $\begin{array}{c}\text { Target } \\
\text { achieve- } \\
\text { ment [\%] }\end{array}$ \\
\hline MULTI GAP 2010 & 397 & $3.01 \pm 1.00$ & 32 & 1143 & $2.84 \pm 0.99$ & 39 \\
\hline \multirow[t]{2}{*}{ PLUS Program } & 114 & $2.83 \pm 0.95$ & 42 & 313 & $2.57 \pm 0.90$ & 50 \\
\hline & \multicolumn{2}{|c|}{$p=0.088$} & $p=0.045$ & \multicolumn{2}{|c|}{$p<0.0001$} & $p=0.001$ \\
\hline
\end{tabular}


Table II. The mean body mass index values and the occurrence of hypertension, smoking and diabetes in the MULTI GAP 2010 basic study and PLUS Program in the patient groups treated by GPs and specialists

\begin{tabular}{|c|c|c|c|}
\hline & GPs & Specialists & Value of $p$ \\
\hline \multicolumn{4}{|c|}{ Body mass index $\left[\mathrm{kg} / \mathrm{m}^{2}\right]$} \\
\hline MULTI GAP 2010 & $28.8 \pm 4.9$ & $29.2 \pm 5.0$ & 0.152 \\
\hline \multirow[t]{2}{*}{ PLUS Program } & $28.9 \pm 5.4$ & $29.4 \pm 4.8$ & 0.399 \\
\hline & $p=0.763$ & $p=0.537$ & \\
\hline \multicolumn{4}{|l|}{ Hypertension [\%] } \\
\hline MULTI GAP 2010 & 93 & 89 & 0.038 \\
\hline \multirow[t]{2}{*}{ PLUS Program } & 82 & 94 & $<0.001$ \\
\hline & $p=0.001$ & $p=0.011$ & \\
\hline \multicolumn{4}{|l|}{ Smoking [\%] } \\
\hline MULTI GAP 2010 & 28 & 28 & 0.782 \\
\hline \multirow[t]{2}{*}{ PLUS Program } & 37 & 31 & 0.228 \\
\hline & $p=0.060$ & $p=0.439$ & \\
\hline \multicolumn{4}{|c|}{ Diabetes mellitus [\%] } \\
\hline MULTI GAP 2010 & 39 & 52 & $<0.001$ \\
\hline \multirow[t]{2}{*}{ PLUS Program } & 30 & 43 & 0.011 \\
\hline & $p=0.089$ & $p=0.009$ & \\
\hline
\end{tabular}

To compare the efficacy of different statins we calculated simvastatin equivalent doses $[10,11]$. Those who did not reach the $2.50 \mathrm{mmol} / \mathrm{l}$ target level had a daily simvastatin dose of $39.4 \mathrm{mg}$, while those who achieved the target were on $42.2 \mathrm{mg}$ (non-significant difference, $p=0.11$ ). During the treatment the doctors also applied ezetimibe as combination therapy in order to achieve the target in addition to statins. The rate of administration of combination therapy was $10 \%$ in the MULTI GAP main study and $22 \%$ in the PLUS Program $(p<0.001)$. The application of combination therapy

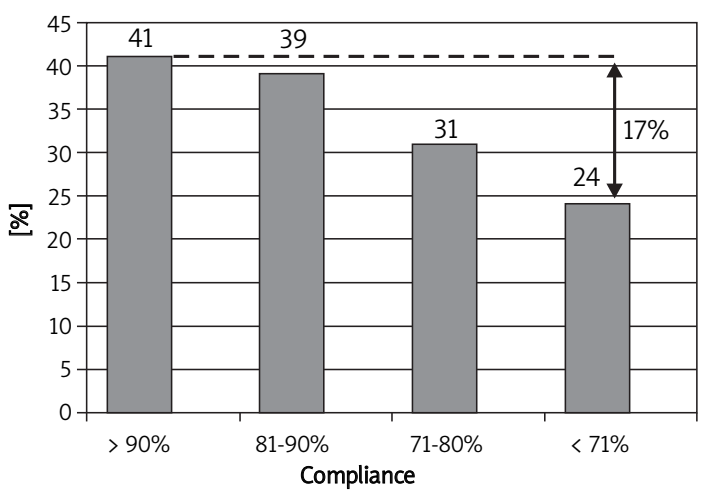

Figure 4. The relationship between the attainment of $2.5 \mathrm{mmol}$ LDL-cholesterol level and the patients compliance in the MULTI GAP study
Table III. The distribution of LDL cholesterol level, body mass index and the occurrence of hypertension, smoking and diabetes according to gender

\begin{tabular}{|c|c|c|c|}
\hline & Men & Women & Value of $p$ \\
\hline \multicolumn{4}{|c|}{ LDL cholesterol level [mmol/l, mean \pm SD] } \\
\hline Total & $2.76 \pm 0.95$ & $2.93 \pm 1.02$ & 0.001 \\
\hline MULTI GAP 2010 & $2.81 \pm 0.96$ & $2.99 \pm 1.03$ & 0.001 \\
\hline PLUS Program & $2.58 \pm 0.89$ & $2.73 \pm 0.96$ & 0.091 \\
\hline \multicolumn{4}{|c|}{ Body mass index $\left[\mathrm{kg} / \mathrm{m}^{2}\right.$, mean $\left.\pm \mathrm{SD}\right]$} \\
\hline Total & $29.2 \pm 4.8$ & $28.9 \pm 5.2$ & 0.227 \\
\hline MULTI GAP 2010 & $29.2 \pm 4.8$ & $28.9 \pm 5.2$ & 0.233 \\
\hline PLUS Program & $29.3 \pm 4.6$ & $29.1 \pm 5.6$ & 0.753 \\
\hline \multicolumn{4}{|l|}{ Hypertension [\%] } \\
\hline Total & 90 & 91 & 0.372 \\
\hline MULTI GAP 2010 & 90 & 91 & 0.517 \\
\hline PLUS Program & 90 & 92 & 0.482 \\
\hline \multicolumn{4}{|l|}{ Smoking [\%] } \\
\hline Total & 36 & 20 & $<0.001$ \\
\hline MULTI GAP 2010 & 35 & 20 & $<0.001$ \\
\hline PLUS Program & 40 & 21 & $<0.001$ \\
\hline \multicolumn{4}{|c|}{ Diabetes mellitus [\%] } \\
\hline Total & 48 & 44 & 0.056 \\
\hline MULTI GAP 2010 & 49 & 47 & 0.405 \\
\hline PLUS Program & 45 & 32 & 0.009 \\
\hline
\end{tabular}

significantly helped to achieve the $2.50 \mathrm{mmol} / \mathrm{l}$ LDL-C target in both MULTI GAP 2010 and the PLUS Program $(p<0.001)$ (Figure 5$)$.

\section{Discussion}

The results of the INTERHEART study showed that in $90 \%$ of cases, well-defined risk factors are responsible for the development of myocardial

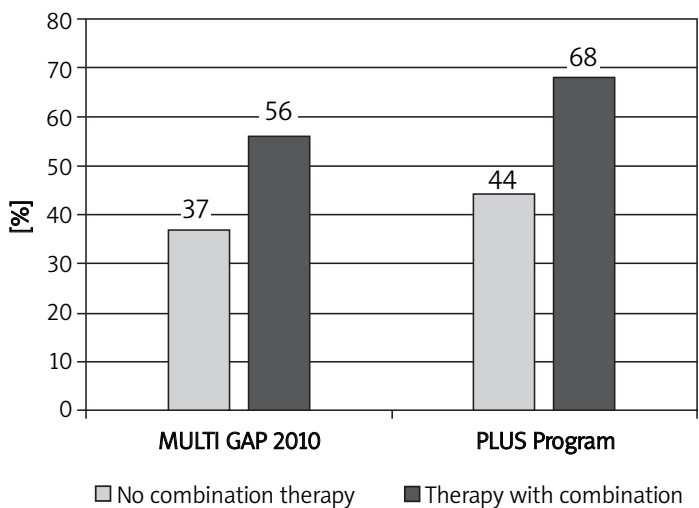

Figure 5. The attainment rate of $2.5 \mathrm{mmol} / \mathrm{LDL}$ cholesterol target level in MULTI GAP 2010 study and PLUS Program according to the application of combination therapy 
infarction [5]. These results give a kind of encouragement to those who are engaged in prevention and to health policy, since they show that CVD is preventable and that a greater role should be given to achieving changes in lifestyle.

The STENO-2 study compares the importance of treatment of 3 major risk factors (hyperlipidaemia, hypertension and diabetes mellitus) in the development of cardiovascular events in type 2 diabetic patients. The 13.3-year follow-up of 80 patients receiving intensive therapy and 80 receiving standard therapy confirmed the primacy of intensive risk factor treatment and of a multifactorial approach $[12,13]$. In the study there was a significant difference in attaining target values of the different risk factors. The best ratio was that of cholesterol, followed by hypertension and $\mathrm{HbA}_{1 \mathrm{c}}$.

The analysis of Yudkin et al., based on results of various intervention and epidemiological studies, compares the number of patients needed to treat for the prevention of one event (NNT = number needed to treat) with the same risk factors. With $1 \mathrm{mmol} / \mathrm{l}$ cholesterol reduction 59.5 patients, with $10 / 5 \mathrm{mmHg}$ blood pressure reduction 61.8 , and with $0.9 \%$ reduction in $\mathrm{HbA}_{1 c} 140.3$ patients have to be treated for 5 years to prevent one fatal or non-fatal heart attack or sudden cardiac death [14]. The STENO-2 study and Yudkin's meta-analysis demonstrate that the incidence of cardiovascular events can be influenced the best by reducing the cholesterol level; this is the activity in which the target levels would be the easiest to attain.

The key element in the prevention guidelines is the adequate reduction of lipids in stable and unstable ischaemic conditions [15]. The last 1.5-2 decades have resulted in the appreciation of lipidlowering therapy in the developed countries and this, with some delay, arrived in Hungary as well. The EUROASPIRE studies also showed that in patients suffering from CHD the treatment of all risk factors improved, but the changes in lipid goal achievements were extremely good $[16,17]$.

The extent of the lipid-lowering therapy is determined by the goal values depending on the risk categories. In its spreading in Hungary the consensus conference held every 2 years has had notable achievements which help to keep the topic of prevention before the public eye. Moreover, the results of conferences are constant subjects of continuous medical education, and publications about the consensus are constant themes in the medical journals. Currently the recommendations of the $4^{\text {th }}$ Hungarian Cardiovascular Consensus Conference are considered as standards in cardiovascular prevention [9].

The publication of outstanding results of the clinical studies performed with statins also contributes to applying more frequently the representatives of this class of drugs in Hungary as well. Data of systematic surveys of recent years show that the LDL-C attainment rate in patients with high cardiovascular risk is continuously increasing. The increased activity of pharmaceutical companies also played an important role in this, on one hand by promoting and propagating the principles of prevention and the results of consensus conferences, and on the other hand by presenting lipid-lowering drugs, including generic statins, at low prices to the colleagues. It has been proved that lipid-level reduction plays a considerable role in the improvement of cardiovascular mortality in Hungary [18] but due to the absence of accurate data its extent cannot be given. The increasing use of combination therapy also contributes to these positive results. In the MULTI GAP 2010 study the application rate of combination treatment was $10 \%$. However, it should be noted that in patients of doctors properly educated by the PLUS Program the administration of combination therapy was more frequent (22\%), which resulted in a significantly greater LDL-C target attainment (Figure 5).

Results of MULTI GAP 2010 taking into account also the trends of previous years show that the upward trend has been broken; the significant improvement observed initially each year is now hardly noticeable. Li et al. in the population-wide representative National Health and Nutrition Examination Survey conducted in the U.S. with a large number of individuals between 1999 and 2006 found a decrease of the LDL-C levels in men from $3.25 \pm 0.03$ to $3.02 \pm 0.02$, and that in women from $3.11 \pm 0.03$ to $2.98 \pm 0.03 \mathrm{mmol} / \mathrm{l}(p<0.001)$ [19]. In Hungary, the observed decrease during the same period $(0.77 \mathrm{mmol} / \mathrm{l}$ for GPs, $0.50 \mathrm{mmol} / \mathrm{l}$ for specialists) was significantly higher, but it should not be forgotten that the latter record came from high-risk patients treated by lipid-lowering drugs, and yet it is noteworthy that the U.S. average LDL-C level is essentially similar to that of high-risk, treated patients of Hungary. Farzadfar et al., analysing global trends, found (not in high cardiovascular risk patients) in higher-income countries (Western Europe, North America and Australia) a $0.2 \mathrm{mmol} / /$ decrease, and in Eastern and Central Europe a $0.2 \mathrm{mmol} / \mathrm{l}$ decrease in LDL-C level during a decade [20].

A favourable change in the frequency of risk factors causes a significant reduction in cardiovascular mortality [21]. According to the results of the LTAP study, the achievement rate of LDL-C target levels rose in 9 countries on average from $18 \%$ to $67 \%$ in 10 years [22]. The Hungarian trends are improving as well, but the results are less favourable in international comparative terms $[15,23,24]$. 
In 2010, besides MULTI GAP, the standard quality measurement of lipid-lowering therapy, a new trial was carried out in which a smaller group of doctors received a special education named the Plus Program. The results proved that education of GPS and specialists can boost further improvement of reaching the target level, i.e. a better knowledge of principles and practices of prevention, and application of the lipid-lowering computer program results in the improvement of treatment. The importance of education is also emphasized in the publication of Katsiki et al. [25].

It is well known that women have less favourable indicators of cardiovascular prevention [26]. Lipid lowering and achieving the targets in Hungary seem to be no exception. Women's LDL-C level was higher by $6.2 \%, 0.17 \mathrm{mmol} / \mathrm{l}$. The trend was similar among male and female patients of the PLUS Program $(0.15 \mathrm{mmol} / \mathrm{l}$ is not a statistically significant difference due to the small sample size), which means that a better understanding of the principles of prevention itself does not lead to more favourable rates. Perhaps the indicators would improve if the training drew more attention to careful treatment of women.

The administration of ezetimibe results in a lower LDL cholesterol level [27]. Our results demonstrate that the frequent use of combination therapy helps to achieve the target levels (Figure 5). In patients reaching the target values, higher statin doses were applied (undoubtedly, the difference was not statistically significant).

The effectiveness of drug therapy largely depends on the therapeutic cooperation of the patients [28]. The meta-analysis of Simpson et al. found a correlation between therapeutic adherence and the occurrence of clinical events, including deaths [29]. Rasmussen et al. studied the relationship of long-term survival and evidence-based pharmacotherapy in post-infarction patients. More than 31 thousand patients were followed and it was concluded that good adherence to statins also led to a reduction in mortality [30]. In our study, we found a linear correlation between the patients' cooperation in compliance of drug taking and achievement of the LDL-C target value (Figure 4). Between the good and bad compliance group there was a $17 \%$ difference in the target level attainment rate, which in the long term would evidently cause a difference in the occurrence of clinical events.

Overall, the 2010 MULTI GAP study showed that the improvement of quality of lipid-lowering therapy in Hungary came to a stop. The results of the PLUS Program suggest that the continuous training of doctors is the key to further improvement. This training must draw attention to women's increased risk and the need for their more careful treatment. Achievement of target values is favourably influenced by improved patient compliance. Each consultation between doctor and patient should draw the patient's attention to the fact that the effectiveness of lipid-lowering therapy will deliver the expected anti-atherosclerotic results and lowering effect on cardiovascular events only if medication compliance is appropriate. Stricter follow-up of patients also improves the therapeutic collaboration. Every lipid-level control should include a revision of the therapy. Our study also confirmed that by applying higher doses of statins together with combination treatment a greater lipid-lowering effect and better target level attainment could be achieved.

\section{Acknowledgments}

The various studies analysed in this paper were conducted by Dendrite Ltd, Hungary. All authors had full access to all the data in the study, take responsibility for the integrity of the data and the accuracy of the data analyses, and agreed to the manuscript as written. The authors have given talks, attended conferences and participated in other trials or advisory boards sponsored by various pharmaceutical companies. This material was written independently, and no company or institution supported the authors financially. No professional writer was involved.

\section{References}

1. World Health Report, WHO 2002 (http://www.who.int/ whr/2002/en/).

2. Heart Health Charter. http://www.heartcharter.eu.

3. Rydén L, Martin J, Volqvartz S. The European Heart Health Charter: towards a healthier Europe. Eur J Cardiovasc Prev Rehabil 2007; 14: 355-6.

4. Atella V, Brady A, Catapano AL et al. Bridging science and health policy in cardiovascular disease: focus on lipid management: A Report from a Session held during the $7^{\text {th }}$ International Symposium on Multiple Risk Factors in Cardiovascular Diseases: Prevention and InterventionHealth Policy, in Venice, Italy, on 25 October, 2008. Atheroscler Suppl 2009; 10: 3-21.

5. Yusuf S, Hawken S, Ounpuu S et al.; INTERHEART Study Investigators. Effect of potentially modifiable risk factors associated with myocardial infarction in 52 countries (the INTERHEART study): case-control study. Lancet 2004; 364 : 937-52.

6. Mark L. Paragh Gy, Karadi I, Reiber I, Pados Gy. Changes in attainment of lipid goals by general practitioners and specialists in patients at high cardiovascular risk in Hungary during 2004-2008. Arch Med Sci 2010; 6: 695-700.

7. Reiber I, Paragh Gy, Márk L. Status report from the abyss - the results from the Hungarian MULTI GAP 2009. Metabolizmus 2010; 8: 137-42.

8. Reiber I, Paragh GY, Márk L, Pados Gy. Becoming more focused therapeutic lipid patterns: results from the Hungarian MULTI GAP. Orv Hetil 2011; 152: 822-7.

9. The IV. Hungarian Cardiovascular Consensus Conference. Metabolizmus 2010; 8 Suppl A: 2-96. 
10. Grundy SM, Cleeman JI, Merz CN, et al.; National Heart, Lung, and Blood Institute; American College of Cardiology Foundation; American Heart Association. Implications of recent clinical trials for the National Cholesterol Education Program Adult Treatment Panel III guidelines. Circulation 2004; 110: 227-39.

11. Roberts WC. The rule of 5 and the rule of 7 in lipidlowering by statin drugs. Am J Cardiol 1997; 80: 106-7.

12. Gæde P, Vedel P, Larsen N, Jensen GVH, Parving HH, Pedersen $\mathrm{O}$. Multifactorial intervention and cardiovascular disease in patients with type 2 diabetes. N Engl J Med 2003; 348: 383-93.

13. Gaede P, Lund-Andersen H, Parving HH, Pedersen O. Effect of a multifactorial intervention on mortality in type 2 diabetes. N Engl J Med 2008; 358: 580-91.

14. Yudkin JS, Richter B, Gale EA. Intensified glucose lowering in type 2 diabetes: time for a reappraisal. Diabetologia 2010; 53: 2079-85.

15. Packard CJ. Benefits of lipid regulation in acute coronary syndrome. Arch Med Sci 2010; 6 (Supl. 1A): S76-82.

16. Kotseva K, Wood D, De Backer G, De Bacquer D, Pyörälä K, Keil U; EUROASPIRE Study Group. Cardiovascular prevention guidelines in daily practice: a comparison of EUROASPIRE I, II, and III surveys in eight European countries. Lancet 2009; 373: 929-40.

17. Jánosi A, Östör E, Borbás S. et al. Data on secondary prevention of coronary artery disease in Hungary and some changes in the last ten years (EUROASPIRE 19952005). Orvosi Hetilap 2010; 151: 1776-82.

18. Jozan P. Crisis and renewal in the epidemiological evolution after the second world war in Hungary. MTA Tarsadalomkutato Központ, Budapest 2008.

19. Li M, Ong KL, Tse HF, Cheung BMY. Utilization of lipid lowering medications among adults in the United States 1999-2006. Atherosclerosis 2010; 208: 456-60.

20. Farzadfar F, Finucane MM, Danaei G, et al. National, regional, and global trends in serum total cholesterol since 1980: systematic analysis of health examination surveys and epidemiological studies with 321 country-years and 30 million participants. Lancet 2011; 377: 578-86.

21. Capewell S, ES, Croft JB, et al. Cardiovascular risk factor trends and potential for reducing coronary heart disease mortality in the United States of America. Bull World Health Organiz 2010; 88: 120-30.

22. Waters DD, Brotons C, Chiang CW, et al.; Lipid Treatment Assessment Project 2 Investigators. Lipid Treatment Assessment Project 2. A Multinational survey to evaluate the proportion of patients achieving low-density lipoprotein cholesterol goals. Circulation 2009; 120: 28-34.

23. Steinberg BA, Bhatt DL, Mehta S, et al. Nine-year trends in achievement of risk factor goals in the US and European outpatients with cardiovascular disease. Am Heart J 2008; 156: 719-27.

24. Hermans MP, Cabezas MC, Strandberg T, et al. Centralized Pan-European survey on the under-treatment of hypercholesterolaemia (CEPHEUS): overall findings from eight countries. Curr Med Res Opin 2010; 26: 445-54.

25. Katsiki N, Mikhailidis DP, Athyros VG, et al. Are we getting to lipid targets in real life? Arch Med Sci 2010; 6: 639-41.

26. Bugiardini R, Yan AT, Yan RT; the Canadian Acute Coronary Syndrome Registry I and II Investigators. Factors influencing underutilization of evidence-based therapies in women. Eur Heart J 2011; e-pub March 7. doi:10.1093/eurheartj/ehr027.

27. Rizzo M, Rini GB. Ezetimibe, cardiovascular risk and atherogenic dyslipidaemia. Arch Med Sci 2011; 7: 5-7.
28. Gitt AK, Drexel H, Feely J, et al. Persistent lipid abnormalities in statin-treated patients and predictors of LDL-cholesterol goal achievement in clinical practice in Europe and Canada. Eur J Cardiovasc Prev Rehabil 2011 Mar 10 [Epub ahead of print].

29. Simpson SH, Eurich DT, Majumdar SR, et al. A metaanalysis of the association between adherence to drug therapy and mortality. BMJ 2006; 333: 15.

30. Rasmussen JN, Chong A, Alter DA. Relationship between adherence to evidence-based pharmacotherapy and longterm mortality after acute myocardial infarction. JAMA 2007; 297: 177-86 